\title{
Social Influence Effects on Automatic Racial Prejudice
}

\author{
Brian S. Lowery and Curtis D. Hardin \\ University of California, Los Angeles
}

\author{
Stacey Sinclair \\ University of Virginia
}

\begin{abstract}
Although most research on the control of automatic prejudice has focused on the efficacy of deliberate attempts to suppress or correct for stereotyping, the reported experiments tested the hypothesis that automatic racial prejudice is subject to common social influence. In experiments involving actual interethnic contact, both tacit and expressed social influence reduced the expression of automatic prejudice, as assessed by two different measures of automatic attitudes. Moreover, the automatic social tuning effect depended on participant ethnicity. European Americans (but not Asian Americans) exhibited less automatic prejudice in the presence of a Black experimenter than a White experimenter (Experiments 2 and 4), although both groups exhibited reduced automatic prejudice when instructed to avoid prejudice (Experiment 3 ). Results are consistent with shared reality theory, which postulates that social regulation is central to social cognition.
\end{abstract}

There is now little debate that racial prejudice and stereotyping can operate automatically - by proceeding effortlessly, unintentionally, outside awareness, and uncontrollably (e.g., Bargh, 1994, 1999; Hamilton \& Sherman, 1994)—yet research has increasingly focused on identifying ways in which automatic prejudice nevertheless may be controlled consciously (reviewed in Bargh, 1999; Devine \& Monteith, 1999). Notably, this endeavor has proceeded largely within parameters defined by dual-processing approaches to social cognition, which postulate that automatic modes of information processing may be refined, corrected, or overridden by controlled modes of information processing (reviews in Chaiken \& Trope, 1999). For example, Devine (1989) postulated that stereotypes are activated automatically upon exposure to a member of a stereotyped group or symbolic equivalent, irrespective of one's conscious intentions, beliefs, or prejudice, whereas the application of stereotypes is sometimes susceptible to conscious control (Devine \& Monteith, 1993; Devine, Monteith, Zuwerink, \& Elliot, 1991; Monteith, 1993; Plant \& Devine, 1998).

Despite the influence of the dual-processing approach, there continue to be questions about both the controllability of applica-

Brian S. Lowery and Curtis D. Hardin, Department of Psychology, University of California, Los Angeles (UCLA); Stacey Sinclair, Department of Psychology, University of Virginia.

This research was funded in part by a grant from the UCLA Center for African American Studies awarded to Curtis D. Hardin as well as UCLA Project 88 and National Science Foundation predoctoral fellowships awarded to Brian S. Lowery. For serving as experimenters, we are grateful to Safiwa Steward, Corey Kosbob, Elizabeth Kirk, Tara Gruenewald, John Hetts, Emily Impett, Mina Kimmerling, Khalisha Jones, Yhunuan Williams, Charlie Ralph, Pam Taylor, and John Updegraff. For helpful comments on drafts, we thank Karen Cheng, Elisheva Gross, Emily Impett, Matt Lieberman, Pamela Riley, and Jim Sidanius.

Correspondence concerning this article should be addressed to Curtis D. Hardin, University of California, Department of Psychology, 1282A Franz Hall, Box 951563, Los Angeles, California 90095-1563. Electronic mail may be sent to hardin@psych.ucla.edu. tion and the automaticity of activation (e.g., Bargh, 1999). The conscious control of stereotype application is assumed to require the unlikely conjunction of at least four conditions, including (a) an awareness that one might invoke a stereotype, (b) a more or less accurate understanding of how the stereotype might affect judgment, (c) the motivation to control the stereotype, and (d) the capacity to act on the motivation (e.g., Bargh, 1999; Devine \& Monteith, 1999). Additionally, a number of recent studies suggest that the activation phase of stereotyping might not be inevitable after all (cf. Bargh, 1999; Blair \& Banaji, 1996; Blair, Ma, \& Lenton, 2001; Dasgupta \& Greenwald, 2001; Fazio, Jackson, Dunton, \& Williams, 1995; Gilbert \& Hixon, 1991; Lepore \& Brown, 1997; Locke, MacLeod, \& Walker, 1994; Macrae, Bodenhausen, Milne, Thom, \& Castelli, 1997; Moskowitz, Salomon, \& Taylor, 2000; Richeson \& Ambady, 1999; L. Sinclair \& Kunda, 1999; Spencer, Fein, Wolfe, Fong, \& Dunn, 1998; Uleman \& Moskowitz, 1994; Wilson, Lindsey, \& Schooler, 2000).

Consistent with the belief that automatic stereotype activation is the product of long-term exposure to particular associations, research on the controllability of stereotype activation has focused most on the impact of long-term, individual motivations to avoid prejudice (Amodio, Harmon-Jones, \& Devine, 2001; Bargh, 1990; Blair et al., 2001; Dasgupta, McGhee, Greenwald, \& Banaji, 2000; Devine, Plant, Amodio, Harmon-Jones, \& Vance, 2001; Monteith, 1993; Moskowitz, Gollwitzer, Wasel, \& Schaal, 1999). For example, experimentally generated counterstereotypical associations temporarily eliminated stereotyped associations of older adults and "skinheads" as indicated by a Stroop interference task (Kawakami, Dovidio, Moll, Hermsen, \& Russin, 2000). This finding is congruent with the hypothesis that people with nonprejudiced motivations may over time learn to associate egalitarian thoughts with members of stereotyped groups, until the new association becomes automatized (e.g., Bargh, 1990, 1997; Moskowitz et al., 1999).

\section{The Social Influence of Automatic Social Cognition}

In contrast to work based on the learned-association approach (e.g., Blair et al., 2001; Dovidio, Kawakami, \& Gaertner, 2000), 
our research has been inspired by contemporary communication theory, which postulates that social interaction is predicated on ongoing mutual perspective taking that is highly routinized, and probably automatic (for reviews see Clark, 1996; Hardin \& Higgins, 1996; Krauss \& Fussell, 1996; Sperber \& Wilson, 1987). From this perspective, even rudimentary social interaction requires at every turn the establishment and maintenance of "common ground," or the mutual perception that interaction participants share the knowledge necessary to sustain the interaction.

One process by which people achieve common ground is to adjust their perspectives and communicative attempts according to inferences they make about the knowledge and attitudes of others (e.g., Krauss \& Fussell, 1991). For example, when asked for directions, people use social categorization cues (such as accents and clothing) to infer whether the request is from a local or an outof-towner, and adjust their directions accordingly; for example, the use of famous landmarks for out of towners and local landmarks for locals (e.g., Isaacs \& Clark, 1987). Schwarz (1994) has identified several ways in which such conversational norms operate in the experimental situation as participants and experimenters tacitly negotiate shared understandings of experimental tasks or questionnaires.

Social cognition research inspired by communication theory implicates a process analogous to the achievement of common ground in social perception, suggesting that even incidental knowledge of a new acquaintance's attitude about a social target is sufficient to influence attitudes and memory about a social target (reviewed in McCann \& Higgins, 1992). In a classic study, for example, Higgins and Rholes (1978) had participants read a brief description of Donald, whose behaviors could be characterized positively as "adventurous" just as easily as they could be characterized negatively as "reckless." Participants read the description with the expectation that they would eventually discuss their impressions of Donald with another participant, who either "kinda liked" or "kinda disliked" him. Careful coding of the discussions indicated that participants not only adjusted their communications toward the ostensible attitudes of their partners, but that the discussion affected their own attitudes and memory about Donald. Participants whose partners were said to like versus dislike Donald communicated more positively about him and later endorsed more positive attitudes about him. Moreover, participants later remembered more positive aspects of the original description when they had interacted with someone who was said to like rather than dislike Donald.

Subsequent research demonstrated that such social tuning effects depend critically on relationship-relevant motives. For example, McCann and Hancock (1983) found that social tuning was more pronounced among participants who valued appropriate adjustment to the situation than among participants who valued attitude consistency, as indicated by Snyder's (1974) selfmonitoring scale. Similarly, Higgins and McCann (1984) demonstrated that high-authoritarian participants tuned more to a highstatus partner than a low-status partner, but low-authoritarian participants tuned more to a low-status partner than a high-status partner. Taken together, these findings suggest that social tuning is determined not only by presumptions about the attitudes of others, as the communication literature suggests, but also by relationshipspecific motives.
Congruent with this approach, people are notoriously adept at social tuning where the expression of prejudice is concerned, although these effects are usually assumed to reflect mere attempts to appear socially desirable rather than genuine attitude change (e.g., Allport, 1954; Crosby, Bromley, \& Saxe, 1980). For example, research involving nationally sampled populations shows that European Americans express markedly less racial prejudice to a Black interviewer than a White interviewer, consistent with the presumption that anti-Black attitudes are less acceptable to Blacks than to Whites (e.g., Kinder \& Sanders, 1996; Schuman, Steeh, Bobo, \& Krysan, 1997). Indeed, the discovery of automaticity in social cognition was due in large part to the development of methodologies designed to bypass social desirability effects in stereotyping and prejudice (e.g., Fazio et al., 1995; Greenwald \& Banaji, 1995). However, the communication approach suggests that social influence may also engender genuine attitude change.

In fact, evidence exists that social tuning may indeed influence private racial attitudes. For example, Blanchard, Lilly, and Vaughn (1991) found that people exhibited less prejudice on a completely anonymous questionnaire in the presence of a confederate (posing as another participant) who expressed a nonracist belief than a confederate who expressed a belief that could be construed as racist. Although participants had no reason to believe that they would ever interact with the confederate, their privately expressed racial attitudes assimilated toward the attitude expressed by the confederate, suggesting that local social norms may influence privately accepted attitudes as well as public expressions of prejudice. More recently, Sinclair and Kunda (1999) found evidence that positive social motivation reduces the activation of negative racial stereotypes in judging an African American target, as indicated by implicit word-fragment-completion and lexical-decision tasks. This finding is striking in part because it appears to contradict the common assumption that the presence of an African American inevitably elicits anti-Black stereotyping and prejudice (Devine, 1989; Dovidio et al., 1997).

\section{Overview of Experiments}

In the experiments reported here we sought to identify conditions in which social tuning might be observed on popular measures of automatic racial prejudice. Research on the public expression of racism demonstrates that social influence effects can be elicited tacitly, by the mere presence of someone whose social category implies their attitude -in this case, that anti-Black attitudes are less acceptable to Blacks than Whites (e.g., Schuman et al., 1997). Hence, we investigated automatic social tuning by assessing automatic prejudice in the presence of a Black versus White experimenter.

This paradigm offers two benefits. Firstly, it examines automatic racial prejudice in the context of actual interethnic contact. Secondly, because common conceptions of automatic social cognition assume that stereotypes are inevitably activated in the presence of a member of a stereotyped group or symbolic equivalent, it methodologically pits acute normative social influence-manipulated by experimenter race-against effects of stereotype activation. If automatic stereotypes of African Americans are essentially negative, as theorists have long assumed (e.g., Allport, 1954; Bargh, 1999; Chen \& Bargh, 1997; Devine, 1989; Devine \& Monteith, 1999), then automatic stereotype activation may lead to 
more automatic anti-Black prejudice in the presence of a Black experimenter than a White experimenter. On the other hand, if habitual social regulatory processes moderate effects of the automatic activation of negative stereotypes, then less automatic racial prejudice may be observed in the presence of a Black experimenter than a White experimenter.

Across four experiments, we used two measures of automatic prejudice and two manipulations of social influence. In Experiment 1, we examined the influence of experimenter race on the automatic racial prejudice of European Americans as assessed by the Implicit Association Test (IAT; Greenwald, McGhee, \& Schwartz, 1998). Experiment 2 replicated Experiment 1 in a sample that included Asian American and European American participants, thereby providing a preliminary investigation of the conditionality of automatic social tuning. In Experiment 2 we also examined the degree to which individual differences in explicit racial attitudes moderate automatic social tuning effects. In Experiment 3 we extended the analysis from effects of tacit social influence to expressed social influence on automatic racial prejudice. Finally, to rule out the possibility that the automatic social tuning effects we find are limited to the IAT, in Experiment 4 we replicated Experiment 2 by using a subliminal priming measure of automatic racial prejudice.

\section{Experiment 1}

To examine the hypothesis that automatic racial prejudice is subject to tacit social influence as instantiated by experimenter race, European American participants completed the IAT in the presence of either a Black or a White experimenter.

\section{Method}

Participants. Thirty-three European American undergraduates (7 men and 26 women) at the University of Virginia participated in exchange for course credit.

Materials and procedure. Automatic racial prejudice was assessed by an IAT measure of automatic cognitive associations, which compares the efficiency with which participants can pair Black versus White names with positive versus negative words (Dasgupta et al., 2000; Greenwald et al., 1998; Rudman, Greenwald, Mellot, \& Schwartz, 1999). Evidence that the IAT reflects automatic attitudes includes demonstrations that (a) the prejudice-incongruent associations are executed less efficiently than prejudice-congruent associations, (b) the IAT can reveal associations participants either do not consciously endorse or do not consciously desire to endorse, and (c) the IAT is unreliably correlated with denotatively related explicit attitudes (but see Devine et al., 2001).

In the procedure, an anti-Black/pro-White attitude (the prejudicecongruent association) is indicated by the degree to which (a) Black names are more efficiently associated with negative words than positive words, and (b) White names are more efficiently associated with positive than negative words. Conversely, a pro-Black/anti-White attitude (the prejudice-incongruent association) is indicated by the degree to which (a) Black names are more efficiently associated with positive words than negative words and (b) White names are more efficiently associated with negative than positive words. Racial prejudice is indexed in the IAT by subtracting the efficiency of incongruent associations from congruent associations. In our experience with the measure across many pilot studies and classroom demonstrations, it is always the case that a substantial number of participants correctly determine that the procedure assesses prejudice. Hence, to control for variations in task awareness, participants were told explicitly that the procedure assesses prejudice before completing the IAT.

We used a paper-and-pencil version of the IAT, in which prejudice scores are derived from the number of judgments participants can make in strictly timed congruent and incongruent association phases. ${ }^{1}$ Judgment $F$ items were presented as a series of single words running down the center of each page, and judgments were indicated by check marks in the appropriate right- and left-hand columns (see the Appendix). The task required participants to categorize simultaneously both names and words as quickly and accurately as possible in two different critical phases. One phase was prejudice congruent, such that a check mark in one column indicated that a name was Black, and a word was negative, and a check mark in the other column indicated that a name was White and a word was positive. The other phase was prejudice incongruent, such that a check mark in one column indicated that a name was Black and a word was positive, and a check mark in the other column indicated that a name was White and a word was negative. Following several blocks of practice trials, automatic prejudice was assessed by the difference in the number of correct categorizations on the critical prejudice-congruent versus prejudiceincongruent phases, each of which was completed in $20 \mathrm{~s}$. (Average trial-to-trial response latencies can be calculated by dividing the number of judgments completed within each phase by 20.) The order of the congnuent and incongruent phases, the side participants checked to categorize the items, and the order of stimulus lists used in the critical phases were completely counterbalanced across participants. None of the counterbalanced factors qualified the reported results in any of the experiments.

Participants completed the task in small groups (ranging in size from 2 to 6) randomly assigned to experimenter race condition. Four female research assistants--two White and two Black - served as experimenters.

\section{Results and Discussion}

Error rates were small-on average iess than $5 \%$-and hence comparable to those reported by Greenwald et al. (1998). ${ }^{2}$

To test the hypothesis that automatic prejudice is subject to social influence, we examined automatic prejudice as a function of experimenter race in a 2 (critical phase: congruent vs. incongruent) $\times 2$ (experimenter race: Black vs. White) mixed-model analysis of variance (ANOVA), with critical phase as the withinsubject variable. ${ }^{3}$ Results replicated previous demonstrations of anti-Black prejudice by showing that participants categorized more items in the congruent phase (Black-negative/White-positive) than in the incongruent phase (White-negative/Black-positive), as indicated by a significant main effect of critical phase, $F(1$, $31)=31.18, p<.001, \eta^{2}=.501$. As predicted, however, experimenter race moderated this effect. As shown in Figure 1, participants exhibited more automatic anti-Black prejudice in the presence of a White experimenter than a Black experimenter, as

\footnotetext{
'Although the IAT we used was not administered on computers (cf. Greenwald et al., 1998), we do not believe it is any more susceptible to controlled processing. Both versions assess the strength of cognitive associations by comparing the efficiency with which compering categorizations can be made. In both versions individuals are consciously aware of all presented stimuli, and equivalently aware of the purpose of the procedure. Hence we believe the pencil-and-paper version of the IAT is no less impervious to strategic misreport than the computer version.

${ }^{2}$ No participants were removed because of excessive errors. In addition, results are essentially identical whether or not errors are included in the prejudice scores.

${ }^{3}$ Across all experiments gender was included as a variable, but was inert except where noted.
} 


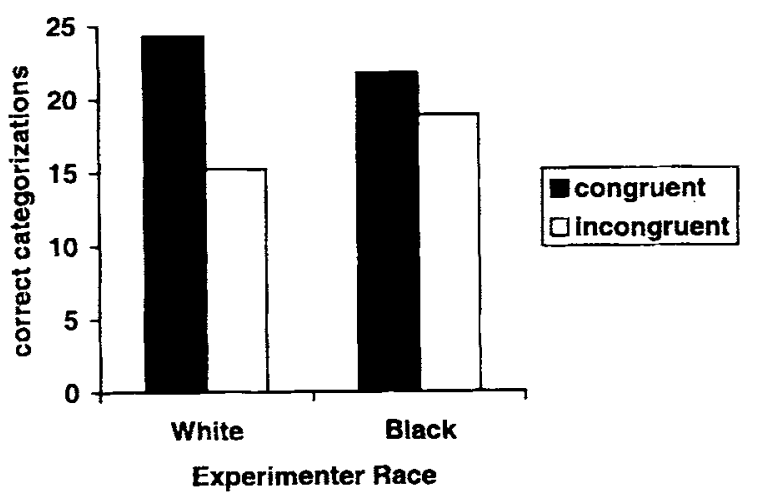

Figure 1. Number of items categorized correctly in congruent and incongruent tasks of the IAT as a function of experimenter race.

indicated by a significant Critical Phase $\times$ Experimenter Race interaction, $F(1,31)=8.44, p<.01, \eta^{2}=.214$. Although participants made more congruent than incongruent categorizations in the presence of a White experimenter, as indicated by a significant simple main effect of critical phase, $F(1,18)=53.19$. $p<.001, \eta^{2}=.747$, this difference disappeared in the presence of a Black experimenter, as indicated by a nonsignificant simple main effect of critical phase, $F(1,13)=2.48, p=.143, \eta^{2}=.158$.

Interestingly, results suggest that the automatic social tuning effect observed in this experiment may have obtained because the Black experimenter elicited stronger positive associations to African American names rather than reducing negative associations. Although the number of congruent items categorized was unaffected by experimenter race, as indicated by a nonsignificant simple main effect of experimenter race, $F(1,31)=1.32, p=.26$, $\eta^{2}=.041$, participants categorized more incongruent items in the presence of a Black experimenter than a White experimenter, as indicated by a significant simple main effect of experimenter race, $F(1,31)=4.80, p<.05, \eta^{2}=.134$.

In summary, results demonstrate that tacit social influence, as instantiated by experimenter race, can affect the expression of automatic racial attitudes. In particular, participants expressed less automatic prejudice in the presence of a Black than a White experimenter. This finding is striking in light of the common assumption that exposure to a member of a stigmatized group inevitably activates prejudice. That is, if the Black experimenters activated negative stereotypes of African Americans, and if negative stereotypes elicit prejudice, then participants might have been expected to exhibit more prejudice in the presence of a Black experimenter than a White experimenter. Although theorists have begun to explore the conditions in which the automatic activation of stereotypes may be inhibited (Blair \& Banaji, 1996; Blair et al., 2001; Dasgupta \& Greenwald, 2001; Gilbert \& Hixon, 1991; L. Sinclair \& Kunda, 1999; Wittenbrink, Judd, \& Park, 2001), stereotype activation is still widely assumed to be an inevitable consequence of exposure to a member of the stereotyped group. Hence, in addition to suggesting that the relationship between stereotyping and prejudice requires further study, these findings underscore the need for investigations of automatic prejudice in the context of other automatic processes, particularly those likely to be operative in interpersonal interactions (e.g., Bargh, 1999).
Although our results are plainly inconsistent with what would be expected if negative stereotype activation elicits automatic prejudice, the stereotype activation explanation can be retained by a simple variation: Perhaps the Black experimenters elicited a positive stereotype "subtype," which in turn elicited a positive automatic evaluation (e.g., Allport, 1954; Brewer, Dull, \& Lui, 1981; Devine \& Baker, 1991; Maurer, Park, \& Rothbart, 1995). From this perspective, a positive subtype elicited by a high-status Black experimenter might reduce prejudice because either some positive affective glow extends to the African American social category or the target group to which participants are responding narrows to individuals like the experimenter. In either case, the potentially positive stereotype evoked by the Black experimenter could plausibly result in a reduction of anti-Black automatic prejudice (cf. Blair et al., 2001; Richeson \& Ambady, 1999; Wittenbrink et al., 2001).

To this we suggest another possible explanation, which places our results in the context of findings of social tuning effects on explicit attitudes (e.g., Blanchard et al., 1991; Higgins \& Rholes, 1978). Shared reality theory suggests one possible mechanism for social tuning effects by postulating that because beliefs require social validation to be maintained they, in turn, have social regulatory functions (Hardin \& Conley, 2000; Hardin \& Higgins, 1996). Specifically, shared reality theory posits that one necessary consequence of a positive social interaction is that participants must find experiences or beliefs upon which shared understandings can be achieved. In short, according to shared reality theory, social cooperation requires the establishment of shared understandings on dimensions relevant to the relationship.

On the basis of shared reality theory's relationship-specificity conjecture, which postulates that social tuning occurs on a given attitude dimension to the degree that it is relevant to the relationship at hand (Hardin \& Conley, 2000), we explored the possibility that automatic social tuning might be reduced or eliminated among participants who feel relatively invulnerable to the charge of anti-Black racism. We speculated that because Black-White relations dominate the discourse on racism in the United States, non-Whites may not chronically perceive their own racism as relevant as Whites do in the presence of Blacks. To explore this possibility, in Experiment 2 we investigated effects of experimenter race on automatic prejudice among Asian Americans as well as European Americans. In addition, explicit race-related attitudes were assessed to examine the possibility that conscious beliefs moderate the social tuning effect and the predicted effect of participant ethnicity.

\section{Experiment 2}

On the basis of shared reality theory's postulate that social tuning occurs on an attitude dimension to the degree that it is perceived to be germane to the relationship, we predicted that Asian Americans would exhibit less automatic social tuning than European Americans, because we assumed that the discourse on race relations in the United States leaves Asian Americans relatively absolved of responsibility for anti-Black discrimination and prejudice (Sears, Citrin, Cheleden, \& van Laar, 1999; Sears \& van Laar, 1999). On the other hand, if stereotype subtyping accounts for the experimenter race effect on automatic prejudice, then one might expect equivalent effects among Asian Americans and Eu- 
European American Participants

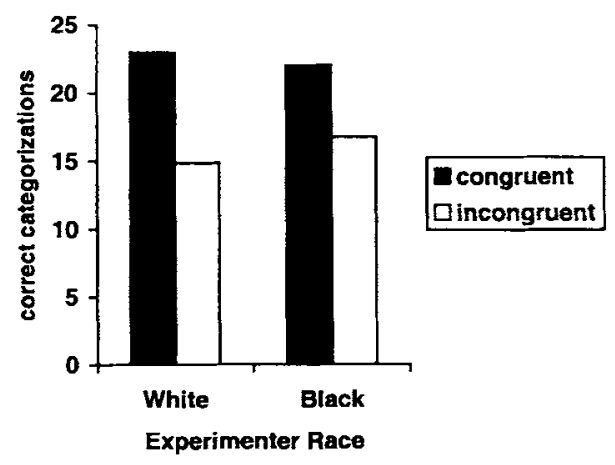

Asian American Participants

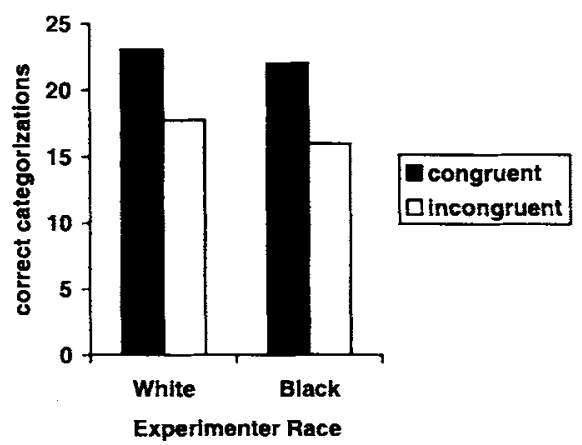

Figure 2. Number of items categorized correctly in congruent and incongruent tasks of the Implicit Association Test as a function of participant ethnicity and experimenter race.

ropean Americans, assuming that both groups are equivalently knowledgeable of African Americans-an assumption our pilot research suggests holds for the undergraduate population at University of California, Los Angeles (UCLA), where Experiment 2 was conducted.

In addition, Experiment 2 investigated the possibility that explicit race-related attitudes might moderate the automatic social tuning effect. Hence, several weeks prior to participating in Experiment 2, participants completed the Modern Racism Scale (MRS; McConahay, Hardee, \& Batts, 1981), the Social Dominance Orientation Scale (SDO; Pratto, Sidanius, Stallworth, \& Malle, 1994), and both the Internal and External Motivation to Respond Without Prejudice scales (IMS, EMS; Plant \& Devine, 1998). To date the relationship between explicit and automatic attitudes has been inconsistent (Blair, 2000); thus this aspect of the experiment was exploratory. In sum, the experiment was a 2 (critical phase: congruent, incongruent) $\times 2$ (experimenter race: White, Black) $\times 2$ (participant ethnicity: European American, Asian American) mixed-model factorial, with critical phase as the within-subjects variable.

\section{Method}

Participants. Two hundred seventy-eight undergraduates $(75$ male, 203 female) from two social psychology classes at UCLA participated in the experiment in exchange for course credit. Of these, 5 did not follow instructions, leaving a sample of 133 European American and 140 Asian American participants who successfully completed the experiment. In addition, we obtained responses to the IMS, EMS, MRS, and SDO scales. ${ }^{4}$ Participants completed the task in groups ranging in size from 15 to 25 people randomly assigned to experimenter race conditions.

Materials and procedure. Experiment 2 used the same measure of automatic prejudice and manipulation of social influence as Experiment 1. Thus, except for the addition of Asian American participants and the use of four new Black experimenters (two male and two female) and four new White experimenters (two male and two female), as well as the addition of explicit measures related to racism, Experiment 2 was an exact replication of Experiment 1.

Several weeks before the focal experiment, participants completed all four explicit measures of racial attitudes. Whereas the EMS $(\alpha=, 77)$ and the SDO scale ( $\alpha=81$ ) demonstrated relatively strong internal reliability, both the IMS $(\alpha=.52)$ and the MRS $(\alpha=.55)$ were considerably less internally consistent. Because of the surprisingly low reliability of both the IMS and the MRS, we assessed their reliability separately for European Americans and Asian Americans to see if one group more than the other accounted for the low reliabilities. In both cases European Americans exhibited lower levels of reliability (IMS, $\alpha=.36$; MRS, $\alpha=.46$ ) than Asian Americans (IMS, $\alpha=.78$; MRS, $\alpha=.74$ ). However, further analysis revealed that the elimination of a single item from each scale markedly improved the reliability of both scales among European American participants (MS, $\alpha=.77$; MRS, $\alpha=.62$ ). Hence, analyses of European American participants' responses used modified versions of these two scales. 5

\section{Results}

To examine the hypothesis that automatic prejudice is subject to social influence, we examined automatic prejudice as a function of experimenter race and participant ethnicity in a 2 (critical phase: congruent vs. incongruent) $\times 2$ (experimenter race: Black vs. White) $\times 2$ (participant ethnicity: European American vs. Asian American) mixed-model ANOVA. As shown in Figure 2, consistent with the postulated role of attitude relevance, results indicate that experimenter race affected the automatic prejudice of European American participants but not Asian American participants, as indicated by a significant Critical Phase $\times$ Experimenter Race $\times$ Participant Ethnicity interaction, $F(1,269)=5.70, p<$ $.05, \eta^{2}=.021$. Although European American participants exhibited significant anti-Black prejudice in the presence of both a White experimenter, $F(1,69)=168.54, p<.001, \eta^{2}=.710$, and a Black experimenter, $F(1,62)=43.80, p<.001, \eta^{2}=.414$, replicating Experiment 1, European American participants exhibited significantly less automatic prejudice in the presence of a

\footnotetext{
${ }^{4}$ The IMS and EMS were collected in both classes, whereas the MRS and the SDO scales were collected in just one class. Hence, the number of participants differs across analyses involving explicit measures.

${ }^{5}$ The "I attempt to act in nonprejudiced ways towards black people because it is personally important to me" item was eliminated from the IMS, and the "The streets are not safe these days without a policeman around" item was eliminated from the MRS. Despite the improved reliability of these two scales without these two items, none of the reported analyses differ significantly if these items are not removed.
} 
Black experimenter than a white experimenter, as indicated by a significant Critical Phase $\times$ Experimenter Race interaction, $F(1$, 131) $=8.10, p<.01, \eta^{2}=.058$. Although the number of items European Americans categorized in the congruent task was unaffected by experimenter race, also replicating Experiment 1, more items were categorized in the incongruent task in the presence of a Black experimenter than a White experimenter, $F(1$, 131) $=3.84, p=.052, \eta^{2}=.028$. In contrast, although Asian American participants exhibited a strong preference for White versus Black names, as indicated by a significant effect of critical phase, $F(1,139)=106.25, p<.001, \eta^{2}=.433$, this prejudice was unaffected by the experimenter race manipulation, as indicated by a nonsignificant Critical Phase $\times$ Experimenter Race interaction $(F<1)$.

A theoretically uninteresting explanation for the insensitivity of Asian American participants to experimenter race is a lack of comprehension of the measure itself. Those unfamiliar with the Asian American population at UCLA might hypothesize lower levels of English fluency among Asian American participants, which could in turn diminish the power to detect systematic changes in their scores in response to the experimenter race manipulation. However, a number of facts belie this hypothesis. Firstly, Asian American participants exhibited levels of internal consistency on par with, and at times exceeding, that of European American participants on explicit measures of racial attitudes. Secondly, Asian American participants made no more incorrect categorizations than European American participants. Finally, across experimental conditions, Asian American participants correctly categorized as many items as their European American counterparts. In summary, results weigh heavily against the hypothesis that Asian American insensitivity to the experimenter race manipulation was due to an inability to comprehend or respond fluently to the measure.

Interestingly, although participant gender did not moderate the predicted Critical Phase $\times$ Experimenter Race $\times$ Participant Ethnicity interaction, there was a significant Critical Phase $\times$ Experimenter Race $\times$ Participant Gender interaction, $F(1,269)=4.00$, $p<.05, \eta^{2}=.015$. This analysis revealed that although male participants were unaffected by the experimenter race manipulation, as indicated by a nonsignificant Critical Phase $\times$ Experimenter Race interaction, $F(1,72)=1.34, p=.250, \eta^{2}=.018$, female participants exhibited the automatic social tuning effect, as indicated by a significant Critical Phase $\times$ Experimenter Race interaction, $F(1,197)=4.41, p<.05, \eta^{2}=.022$. Although this unpredicted effect is statistically independent of the predicted ethnicity effect, it is interesting in its own right. We have since replicated this finding in experiments that directly implicate interpersonal liking as a moderator of automatic social tuning effects (S. Sinclair, Lowery, \& Hardin, 2001).

Our exploration of the role of explicit attitudes in the observed automatic social tuning effects addressed three principally distinct issues: (a) whether European Americans and Asian Americans are differently concerned about their own anti-Black prejudice, (b) whether individual differences in race-related attitudes predict levels of automatic prejudice, and (c) whether individual differences in racism-related attitudes moderate the automatic social tuning effect. Preliminary analysis replicated Plant and Devine's (1998) finding that the internal and external subscales of the motivation to control prejudice were uncorrelated. Hence, each subscale was analyzed independently.

Ethnicity and attitudes. Broadly consistent with the hypothesis that Asian Americans may be less personally concerned about anti-Black prejudice than European Americans, analysis of the IMS indicated that European Americans were more internally motivated to respond without prejudice $(M=7.61, S D=1.40$ ) than Asian Americans $(M=7.09, S D=1.14), t(206)=2.63, p<$ 01. In addition, Asian Americans $(M=3.38, S D=1.32)$ were more willing to express explicitly racist attitudes than European Americans $(M=2.56, S D=1.12$ ), as assessed by the MRS, $t(96)=3.30, p<.001$. Not surprisingly, analysis of the EMS revealed that Asian Americans $(M=4.28, S D=1.96)$ and European Americans ( $M=3.92, S D=1.94$ ) were equally motivated, by external pressures, to respond without prejudice, $t(206)=1.35, p=.18$. Participant ethnicity was unrelated to the SDO scores $(t<1)$.

Explicit attitudes and automatic prejudice. Replicating the generally unreliable relation between implicit and explicit attitudes (e.g., Blair, 2000), results reveal that automatic prejudice was uncorrelated with all four measures of explicit attitudes (as shown in Table 1). However, relationships among the explicit measures replicated previous findings (e.g., Plant \& Devine, 1998; Pratto et al., 1994).

To test for the possibility that the IMS and EMS interactively predicted automatic prejudice, we created an interaction term and regressed automatic prejudice onto this term. (Aiken \& West, 1991). In contrast to findings reported by Devine et al. (2001) and Amodio et al. (2001), in which people rated both high on the IMS and low on the EMS exhibited less implicit prejudice than any other group, we found no evidence of this on automatic prejudice as assessed by the IAT.

Explicit attitudes and automatic social tuning. Analyses exploring the possibility that individual differences in explicit measures of racial attitudes moderate automatic social tuning revealed no significant effects on any of the four explicit measures. Although these null findings are broadly consistent with unreliable

Table 1

Correlations Between Explicit Measures and Automatic Anti-Black Prejudice

\begin{tabular}{lccccr}
\hline Measure & IAT score & EMS & IMS & MRS & SDO \\
\hline IAT score & - & & & & \\
EMS & & & & & \\
$r$ & .03 & - & & & \\
$n$ & 208 & & & & \\
IMS & & & & & \\
$r$ & -.01 & .06 & - & & \\
$\quad n$ & 208 & 208 & & & - \\
MRS & & & & \\
$r$ & .03 & .19 & $-.38^{*}$ & - & \\
$n$ & 98 & 98 & 98 & & \\
SDO & & & & \\
$r$ & .09 & .15 & $-.35^{*}$ & $.56^{*}$ & - \\
$n$ & 98 & 98 & 98 & 98 & \\
\hline
\end{tabular}

Note. IAT $=$ Implicit Association Test; EMS = External Motivation scale; IMS = Internal Motivation scale; MRS = Modern Racism Scale; SDO $=$ Social Dominance Orientation Scale.

$* p<.001$. 
correlations between implicit and explicit attitudes, they nevertheless pose a problem for shared reality theory, which postulates that social tuning is a necessary consequence of interpersonal relationship concerns. Alternatively, to the extent that social tuning is a function of interpersonal relationship motivations as shared reality theory postulates, internal motivation to respond without prejudice might not moderate automatic social tuning because it is a poor proxy for interpersonal relationship motivations.

\section{Discussion}

Experiment 2 demonstrated that European Americans exhibited less automatic prejudice in the presence of a Black experimenter than a White experimenter, replicating Experiment 1. Yet Asian American participants were unaffected by the experimenter race manipulation. These results are broadly consistent with shared reality theory, which postulates that social tuning should occur only on attitude dimensions perceived to be relevant to the relationship at hand. Preliminary support for this hypothesis was suggested by the finding that Asian Americans expressed less explicit concern about their personal anti-Black prejudice, implying less normative pressure to express egalitarian views than that experienced by European American participants. However, despite the plausibility of this explanation, we found no evidence that motivation to control prejudice accounts for participant ethnicity differences in automatic social tuning. Although social influence instigates a process that hinders the automatic activation of racial prejudice, explicit differences in personal desire to respond without prejudice did not moderate the effect. However, more recent experiments provide support for the hypothesis that specifically interpersonal relationship motivation does moderate automatic social tuning effects (S. Sinclair et al., 2001).

Although results of Experiment 2 do not irrevocably refute the subtyping explanation, added assumptions are required to explain the lack of an experimenter race effect on automatic prejudice among Asian Americans. Either Asian Americans and European Americans do not share the same subtypes of Blacks, or they activate different subtypes in response to the type of Blacks represented by our experimenters. While plausible, we have no direct evidence for either possibility. Furthermore, the finding that Asian Americans and European Americans are equally fluent in responding to both the explicit measures and the IAT is inconsistent with the idea that Asian Americans are less culturally fluent. Finally, Asian Americans and European Americans at UCLA report spending the same amount of time with Blacks (Lowery, Hardin, \& Sinclair, 2000). Hence, we think it unlikely that European American participants have more sophisticated subtypes than their Asian American counterparts at UCLA.

If, as posited by shared reality theory, attitude relevance moderates the effect of social influence, then manipulating the relevance of racial prejudice to the relationship with the Black experimenter should cause a shift in racial attitudes among all participants. In contrast, the subtyping explanation would predict that such a manipulation would have no effect on levels of automatic prejudice. From this perspective, participants' representation of the Black experimenter accounts for the shifts in automatic prejudice, and there is no reason to expect an attitude relevance manipulation to affect this representation. Thus, in Experiment 3 we replaced the tacit manipulation of social influence by experi- menter race with a manipulation of attitude relevance. More specifically, Black experimenters either asked participants not to be prejudiced or gave no such instruction, thereby expressly manipulating the relevance of racial prejudice to participants' relationship with the experimenter. If attitude relevance accounts for the observed moderation of social tuning by participant ethnicity, then this manipulation should result in equivalent levels of social tuning for both European Americans and Asian Americans. However, because there is no reason to expect the motivation manipulation to impact perceptions of the experimenter from the perspective of the subtyping explanation, the motivation manipulation should not affect levels of automatic prejudice. In addition, the motivation manipulation provides a new, to date uninvestigated, test of the hypothesis that conscious goals directly related to interpersonal relationship regulation can instigate processes that inhibit the automatic activation of attitudes.

\section{Experiment 3}

Moderation of the social tuning effect by an experimental manipulation of attitude relevance would provide converging evidence for the shared reality theory explanation of the observed differences in automatic social tuning between Asian American and European American participants. In Experiment 3 we tested for this moderation by manipulating the instructions provided to participants. Half of the participants were instructed to avoid prejudice and half were not. In all conditions the IAT was administered by a Black experimenter. We hypothesized that although the attitudes expressed on the IAT may not be chronically relevant to Asian American relationships with Blacks, Asian Americans are capable of perceiving the relevance of prejudice when expressly requested to do so. Hence, we anticipated that experimental instructions to avoid racism would have the same effect on Asian Americans as European Americans.

\section{Method}

Participants. One hundred fifty-seven UCLA undergraduate students (86 European American and 71 Asian American; 53 men and 104 women) enrolled in a social psychology class participated in the experiment as a class demonstration.

Materials and procedure. In Experiment 3, we used the same measure of automatic racial prejudice as in Experiments 1 and 2 . However, the procedure of Experiment 3 differed from the one used in Experiment 2 in two ways. First, all experimenters were Black. Second, relevance was manipulated by telling half of the participants that "your job is to be as nonprejudiced as possible." This instruction was omitted in the control condition. All other instructions were equivalent across conditions and identical to those given in Experiments 1 and 2

\section{Results and Discussion}

To examine the hypothesis that both Asian Americans and European Americans would exhibit automatic social tuning as a function of explicit social influence, we analyzed automatic prejudice in a 2 (critical phase: congruent vs. incongruent) $\times 2$ (instructions: explicit vs. tacit) $\times 2$ (participant ethnicity: Asian American vs. European American) mixed-model ANOVA, with critical phase as the within-subject variable. As shown in Figure 3, results indicate that explicit experimenter instructions to avoid 
European American Participants

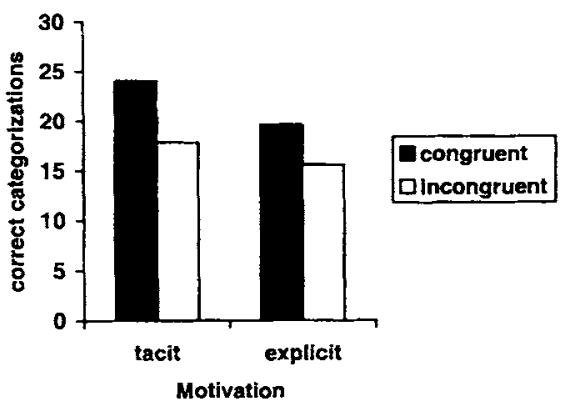

Asian American Participants

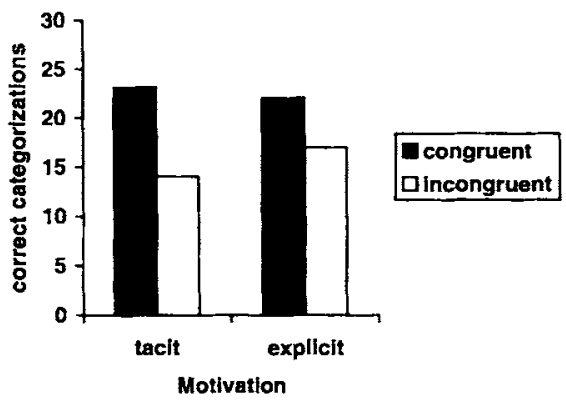

Figure 3. Number of items categorized correctly in congruent and incongruent tasks of the Implicit Association Test as a function of participant ethnicity and instruction type.

prejudice reduced automatic prejudice. Participants exhibited significant levels of automatic prejudice as indicated by a significant main effect of critical phase, $F(1,153)=137, p>.001, \eta^{2}=$ 472. However, this effect was moderated by Instructions, as indicated by a significant Critical Phase $\times$ Instruction interaction, $F(1,153)=6.72, p<.01, \eta^{2}=.042$. As predicted, the magnitude of this effect was statistically equivalent for European American and Asian American participants, as indicated by a nonsignificant three-way interaction $(F<1)$. Probing of the Critical Phase $\times$ Instruction interaction revealed that participants expressed significant prejudice in both instruction conditions. However, there was a larger effect of critical phase in the tacit condition, $F(1,80)=$ $100.62, p<.001, \eta^{2}=.557$, than in the explicit condition, $F(1$, $73)=41.87, p<.001, \eta^{2}=.358$. Further analyses revealed that unlike the pattern in Experiments 1 and 2, more items were categorized in the prejudice-congruent task in the tacit than in the explicit condition, as indicated by a simple main effect of instructions, $F(1,156)=4.97, p<.05, \eta^{2}=.031$, whereas the number of correct categorizations on the prejudice-incongruent task was unaffected by instructions $(F<1)$.

Hence, results of Experiment 3 provide converging evidence that attitude relevance moderates automatic social tuning effects. Although Asian Americans did not exhibit automatic social tuning in Experiment 2, in which social influence was tacit, their social tuning was equivalent to European Americans when attitude relevance was explicit. Notably, careful postprocedure probing indicated that despite effects of explicit instructions, participants reported being unable to deliberately manipulate their IAT performance.

These results represent a fundamental challenge to current understandings of automaticity because automatic measures are typically defined as being impervious to conscious deliberation. However, if a conscious goal evokes an automatic process that competes with the activation of automatic prejudice, then it is possible that conscious intent might, in the right circumstances, reduce the level of automatic prejudice expressed (see Bargh, 1999).

Of course, the more parsimonious-albeit less theoretically interesting explanation-is that the IAT does not measure automatic attitudes alone. Despite the widespread use of the IAT as an automatic measure of attitudes, the lack of correlation between explicit racial attitudes and the IAT, and participant reports of an inability to consciously manipulate the measure, there is still a possibility that the observed shift was the result of strategic task manipulation. If so, the effects demonstrated in Experiments 1-3 would be attributable to mundane task manipulation. To corroborate our claim that results of Experiments 1-3 reflect effects on automatic attitudes, in Experiment 4 we used a subliminal priming measure of automatic prejudice, which precludes the possibility of mundane task manipulation.

\section{Experiment 4}

The fact that participants are consciously aware that the IAT assesses their race-related associations raises the possibility that the social tuning effects observed in Experiments 1-3 may be attributable to mundane task manipulation rather than to competing automatic processes elicited by social influence. Hence, it is important to demonstrate that the automatic social tuning effect generalizes to a measure of automatic attitudes that completely precludes conscious task manipulation. To do so, in Experiment 4 we used a subliminal priming procedure to assess automatic racial prejudice (e.g., Bargh, Chen, \& Burrows, 1996; Bargh \& Pietromonaco, 1982; Chen \& Bargh, 1997; Devine, 1989; Dovidio et al., 1997; Lepore \& Brown, 1997; Wittenbrink, Judd, \& Park, 1997).

\section{Method}

Participants. Twenty-three UCLA undergraduate students enrolled in an introductory methods course participated in the experiment as part of a class demonstration. One participant failed to complete the task, which left 13 European Americans and 9 Asian Americans in the reported analyses. ${ }^{6}$

Materials and procedure. Participants were randomly assigned to one of two groups, and were taken to two separate computer laboratories. A Black experimenter conducted the experiment in one laboratory, and a White experimenter conducted the experiment in the other. To enhance

\footnotetext{
${ }^{6}$ Although the number of participants in each cell was small, it is important to note that the mean for each prime-target combination was composed of the mean of 26 observations per participant with that combination. For this reason, the mean of each cell exhibits a high degree of stability reflected in relatively small standard errors, which allows for the detection of systematic variance despite the relatively small cell sizes
} 
comparability to the three previous experiments, participants were told that the task assessed prejudice. Participants were then told that they would see a series of flashes followed by either the word good or the word bad. Participants judged target words as quickly and accurately as possible by pressing the key labeled $G$ when the word was good or the key labeled $B$ when the word was bad.

Automatic prejudice was assessed by measuring the response latency to identify the words good and bad after subliminal exposure to White and Black faces. In this procedure, automatic anti-Black prejudice is indicated by the degree to which responses are quicker to bad than good after exposure to Black faces, and pro-White prejudice is indicated by the degree to which responses are quicker to good than bad after exposure to White faces. Black-and-white photographs of 26 White faces and 26 Black faces, taken from a recent non-UCLA yearbook served as primes. Each trial began with a focal cue of three asterisks, centered on the display. A forward mask was then presented for $100 \mathrm{~ms}$, a prime face for $17 \mathrm{~ms}$, a backward mask for $200 \mathrm{~ms}$, and then a target (good or bad) appeared until the judgment was entered (stimulus onset asynchrony [SOA], $217 \mathrm{~ms}$ ). Experimental trials were separated by a $1,000-\mathrm{ms}$ intertrial interval during which time the screen was blank. The focal cue and target words were centered on the screen, but the masked primes were presented parafoveally, offset from center 300 pixels horizontally and 200 pixels vertically in four presentation locations. Across trials the primes were presented randomly across the four locations. In careful probing following the task, none of the participants reported awareness that any faces were presented.

Each prime face was paired with both the word good and bad such that each face appeared twice, yielding a total of 104 trials. Prior to the critical trials, participants completed three practice trials followed by a screen that required experimenter instruction to continue. Participants then completed 15 buffer trials that led seamlessly into the critical experimental trials. Both the practice and buffer trials were identical to the experimental trials except that masks were presented without faces. The practice and buffer trials appeared in the same order for all participants, but the experimental trials were presented randomly for each participant.

\section{Results}

Results indicate that automatic social tuning was exhibited by European Americans but not Asian Americans, replicating Experiments 1 and 2. Consistent with conventional procedures of dealing with response latency data, responses either three standard deviations above or three standard deviations below the mean for all participants were eliminated, and the remaining response latencies were log transformed to normalize the distribution (Ratcliff, 1993). Log transformations of the raw response latencies were averaged for each participant within each prime condition. These scores were then subjected to a 2 (prime race: White vs. Black) $\times 2$ (target word: good vs. bad) $\times 2$ (experimenter race: White vs. Black) $\times 2$ (participant ethnicity: European American vs. Asian American) mixed-model ANOVA.

As shown in Figure 4, which presents the means in milliseconds, results reveal that although European American participants exhibited automatic social tuning Asian American participants did not, as indicated by a significant Prime Race $\times$ Target Word $\times$ Experimenter Race $\times$ Participant Ethnicity interaction, $F(1$, 18) $=5.04, p<.05, \eta^{2}=.219$. In the presence of a White experimenter, European Americans exhibited the standard pattern of automatic racial prejudice in which responses were faster to the

\section{European American Participants}

White Experimenter

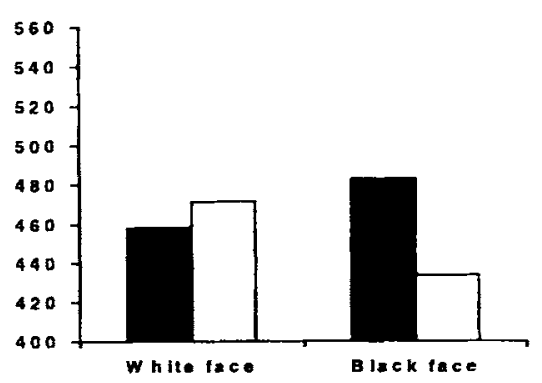

B lack Experimenter

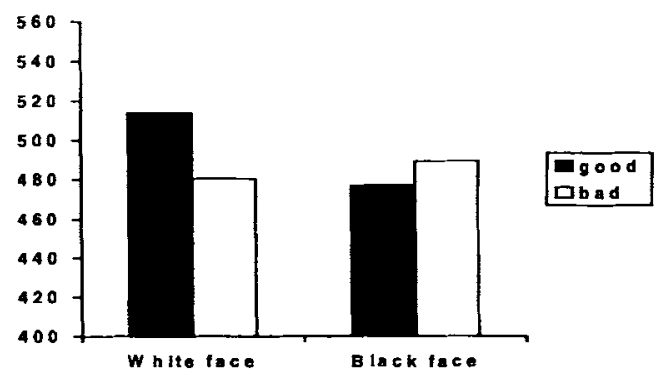

Asian American Participants

White Experimenter

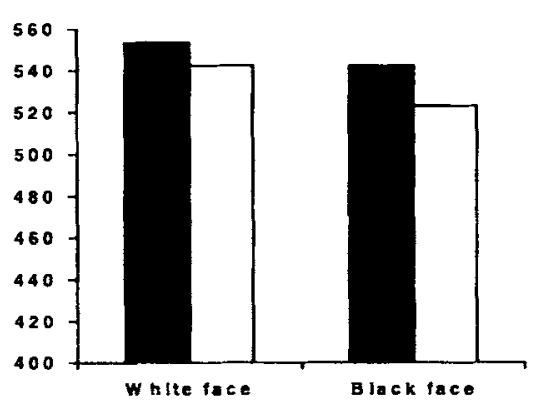

Black Experlmenter

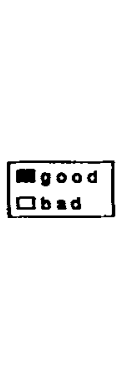

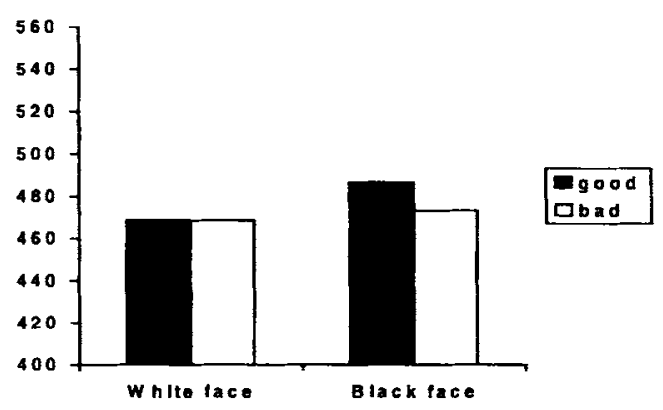

Figure 4. Response latencies in milliseconds to judge the target words good and bad for Asian American and European American participants as a function of prime race and experimenter race. 
word bad than good after Black faces but faster to the word good than bad after exposure to White faces, as indicated by a marginally significant Prime Race $\times$ Target Word interaction, $F(1$, $5)=5.27, p=.07, \eta^{2}=.513$. Although the Prime Race $\times$ Target Word interaction for European Americans in the presence of a Black experimenter was not significant, $F(1,6)=2.52, p=.16$, $\eta^{2}=.296$, it was a significant reversal from the pattern observed in the presence of a White experimenter, as indicated by a significant Experimenter Race $\times$ Prime Race $\times$ Target interaction, $F(1$, 11) $=7.87, p<.05, \eta^{2}=.417$. In contrast, Asian Americans responded equally quickly to the words good and bad after both White and Black faces $(F<1)$; this pattern was unaffected by experimenter race $(F<1)$.

\section{Discussion}

Results of Experiment 4 extend the finding of automatic social tuning to a second measure of automatic racial prejudice. Taken together, Experiments 1-4 demonstrate that social tuning occurs on automatic racial prejudice whether measured by the IAT or a subliminal priming technique. Replicating results of Experiment 2, European American participants exhibited less automatic prejudice in the presence of the Black experimenter than a White experimenter, but Asian Americans were unaffected by the experimenter race manipulation. Interestingly, among European Americans prejudice was not just reduced in the presence of a Black experimenter, but was significantly reversed.

Notably, although Experiment 4 replicated the finding that social tuning occurs for European Americans but not Asian Americans, the prejudice levels exhibited by both groups might appear to be different than in the previous IAT experiments. That is, although the presence of the Black experimenter reduced prejudice for European Americans on the IAT, it significantly reversed prejudice on the subliminal priming procedure. However, the apparently different effects across automatic prejudice measures are not principally incompatible. The subliminal priming measure assesses associations toward Whites and Blacks independently, whereas the IAT assesses attitudes toward Blacks by methodologically imposing a comparison to attitudes toward Whites.

Although Asian Americans exhibited no significant prejudice toward either Whites or Blacks on the subliminal priming measure, this did not in itself preclude finding evidence of social tuning. For example, there is nothing about responding equally quickly to the target words after Black faces in the presence of a White experimenter that in principle or practice precludes them from responding more quickly to good than bad after Black faces in the presence of a Black experimenter. Affectively neutral or ambivalent attitudes can change; they just did not among Asian Americans in this experiment as a function of experimenter race.

As with Experiments 1 and 2, the finding that European American prejudice changes as a function of experimenter race is broadly consistent with a stereotype subtyping explanation, in which presumably positive stereotypes associated with the black experimenters led to a reduction in automatic prejudice. However, the replication of no experimenter race effect among Asian Americans poses a problem for the subtyping explanation. Given that Asian Americans report having the same amount of contact with African Americans as their European American counterparts, it seems unlikely that European Americans have more highly devel. oped subtypes than Asian Americans. However, it is possible that European Americans are more practiced at activating a particular positive subtype than Asian Americans. Perhaps a better understanding of the character of African American relations with Asian Americans versus European Americans would suggest how subtypes might indeed account for these effects. Such a finding would not necessarily challenge our favored explanation. Shared reality theory explains attitude change as a function of interpersonal relationship concerns, and postulates that the specific component of attitude that changes-whether affective, cognitive, or behavioral-will do so as a function of whether it has been chronically implicated in the regulation of the given relationship in the past (e.g., Hardin \& Rothman, 1997) or is established as situationally relevant to interpersonal relationship regulation. Hence, shared reality theory expressly implies that there should be numerous conditions in addition to those identified in Experiment 3 in which social tuning on automatic prejudice should obtain.

In summary, Experiment 4 extended the finding of automatic social tuning among European Americans to a subliminal priming measure of automatic prejudice, thereby refuting the hypothesis that the social tuning effects we describe are limited to the IAT or explicit attitude measures. Replicating the finding with a subliminal priming procedure provides the strongest evidence possible, given current technology, that social tuning on automatic prejudice may occur. Finally, Experiment 4 replicated the finding that automatic social tuning on anti-Black prejudice obtained for European American but not Asian American participants, providing converging, if indirect, evidence of the role of attitude relevance in modulating social tuning effects.

\section{General Discussion}

Taken together, the four experiments presented here provide evidence that automatic racial attitudes are subject to both tacit and explicit social influence. Across two measures of automatic prejudice, European Americans but not Asian Americans exhibited less automatic prejudice in the presence of a Black experimenter than a White experimenter. Experiment 3 demonstrated that explicit experimental instruction to avoid racism reduced automatic prejudice for European Americans and Asian Americans alike.

Although results of Experiments 1-3 could be construed as evidence of the IAT's reactivity, we believe that the measure is essentially invulnerable to mundane misrepresentations in typical experimental conditions. In particular, Experiment 3 demonstrated shifts in automatic racial attitudes as a function of explicit instructions to minimize prejudice. However, from our perspective, change in automatic attitudes as a function of social context does not reflect mundane manipulation, but rather predictable changes in attitudes as a lawful function of interpersonal relationship concerns. Experiment 4 added credence to this claim by utilizing a methodology that precludes the possibility of mundane misreport, yet revealed the same general pattern of social tuning as shown by the IAT. This not only demonstrates that automatic social tuning is not limited to experiments in which the IAT is used, but also that the IAT behaves like a subliminal priming measure.

Hence, our results contradict the assumption that automatic prejudice is inevitably activated by the presence of a member of a negatively stereotyped group, and thereby may represent a challenge to existing theories of automatic stereotyping and prejudice. 
The reduction of automatic prejudice shown in each of the experiments appears to be inconsistent with the notion that African Americans automatically activate negative evaluative responses. Moreover, the finding that explicit motivation influences automatic prejudice is not implied by a subtyping explanation alone.

\section{Explaining Automatic Social Tuning}

We have suggested that our results are consistent with shared reality theory, which postulates that social tuning is a necessary consequence of positive social interaction along relationshiprelevant lines. Shared reality theory not only postulates a mechanism by which social tuning effects might be obtained, but also delineates conditions in which social tuning should be absent. Consistent with the role of attitude relevance posited by shared reality theory, social tuning on automatic racial prejudice was observed for European Americans but not Asian Americans under conditions that left the relevance of the attitude-relationship connection tacit. Given historical and current circumstances in the United States, which make anti-Black racism a particular responsibility of European Americans, it is not surprising that European Americans more than Asian Americans view their personal prejudice as immediately relevant to their interpersonal relationships with African Americans. In contrast, Asian Americans, as victims in their own right of racism in the United States, may feel that their own anti-Black prejudice is not as immediately relevant in interpersonal interactions with African Americans. Finally, however, when experimenter instructions made prejudice explicitly relevant, Asian Americans socially tuned as much as European Americans.

Although our results are consistent with shared reality theory, it is important to acknowledge that the experiments reported here do not provide direct evidence of the operation of the central mechanism postulated by the theory; namely, that interpersonal relationship regulation mediates automatic social tuning. We have speculated that measures focusing on interpersonal motivation (rather than motivation about prejudice per se) would facilitate identifying such an effect-a hypothesis now supported in other experiments on automatic prejudice (S. Sinclair et al., 2001). Additionally, in part because merely imagining a social target elicits perspective-taking-like attitude shifts (Galinsky \& Moskowitz, 2000; Pham \& Hardin, 2001; S. Sinclair, 1999), we believe that demonstrations that imagining a counterstereotypical social target reduces automatic stereotyping are broadly consistent with shared reality theory (e.g., Blair et al,, 2001), and demonstrations that increasing the likability of a target group reduces automatic prejudice are even more telling (e.g., Dasgupta et al., 2000; Wittenbrink et al., 2001). Of course, given that the malleability of automatic stereotyping and prejudice is a new discovery, much work remains to document all relevant mechanisms and conditionality. Finally, however, we cannot help but note that some seemingly attractive explanations positing accessibility as a causal mechanism can become dangerously circular-for example, explaining the malleability of automatic stereotyping in terms of changes in stereotype accessibility alone.

\section{Some Implications for Dual-Process Models of Attitudes}

Dual-process models, which counterpose automatic and controlled information processing, inevitably elicit the question of whether automatic attitudes can be consciously or intentionally controlled. Emerging evidence might suggest that the answer is yes (e.g., Blair et al., 2001; Dasgupta \& Greenwald, 2001). For example, in our Experiment 3, participants exhibited reduced automatic racial prejudice simply by being asked to be as unprejudiced as possible. However, we believe that the answer is closer to no. We have acknowledged that conscious intentions may have indirect effects by initiating the automatic processes more proximally responsible for observed automatic attitude shifts, congruent with an argument suggested by Bargh (1999). Yet even this solution calls for a description of the source of conscious intent. Although we are hardly in a position to solve this problem, we do believe that there are important pitfalls to avoid. In particular, we believe that appeals to conscious or intended processes that are not themselves clearly grounded in social or other determining factors are essentially appeals to magic. For example, the argument that the IAT merely measures cultural associations, whereas explicit attitudes are determined by personal evaluations (e.g., Karpinski \& Hilton, 2001), does not undermine the value of the IAT unless we accept the assumption that personal evaluations are more than simple associations. Furthermore, such views of attitudes suffer from a potentially fatal shortcoming illustrated by the following question. If attitudes do not represent associations generated by experience what exactly do they represent? To assert that attitudes are personal evaluations is to offer an "explanation" that simply begs the question. Where do these personal evaluations come from, if not from experience with associations in the actor's environment? This question is not meant to suggest that the context-sensitive associations likely tapped by the IAT and similar measures necessarily represent "true" attitudes, but simply to point out that the nature of what constitutes a true attitude requires honest discussion.

\section{Conclusion}

In conclusion, conceptualizing automatic prejudice as unresponsive to changes in social context is misguided. The heat of interpersonal interaction may elicit any number of processes, automatic and otherwise, which likely combine to determine the activation and application of stereotypes and prejudice (e.g., L. Sinclair \& Kunda, 1999). The effect of social influence reported here suggests one such process, and in so doing makes clear the need for more sophisticated models of automatic prejudice and stereotyping.

Regardless of the particular mechanism by which prejudice is reduced, these experiments are optimistic in terms of the ability of even overlearned automatic attitudes to shift in response to positive interpersonal contact. However, these results do not challenge the importance of the methodological control of purposeful misrepresentation still offered by automatic measures. Hence, the question is not whether attitudes can be changed, but rather if attitude change represents the best route to a more egalitarian society. While attitude malleability may provide a source of optimism, it also generates reason for pause. If attitudes readily change from situation to situation, to what extent can they serve as the basis for long-term stable change? We maintain that efforts to create stable societal change should focus not on changing attitudes, but rather on the situations that create these attitudes. From this perspective, our findings suggest situational changes that might best accomplish this goal. 


\section{References}

Aiken, L. S., \& West, S. G. (1991). Multiple regression: Testing and interpreting interactions. Thousand Oaks, CA: Sage.

Allport, G. W. (1954). The nature of prejudice. New York: AddisonWesley.

Amodio, D. M., Harmon-Jones, E., \& Devine, P. G. (2001). The emotional and physiological components of race bias: Individual differences in attention- and emotion-modulated startle eyeblink responses. Manuscript submitted for publication.

Bargh, J. A. (1990). Auto-motives: Preconscious determination of social interaction. In E. T. Higgins \& R. M. Sorrentino (Eds.), Handbook of motivation and cognition: Foundations of social behavior (Vol. 2, pp. 93-130). New York: Guilford Press.

Bargh, J. A. (1994). The four horsemen of automaticity: Awareness, intention, efficiency, and control in social cognition. In R. S. Wyer Jr. \& T. K. Srull (Eds.), Handbook of social cognition (Vol. 1, pp. 1-40). Hillsdale, NJ: Erlbaum.

Bargh, J. (1997). The automaticity of everyday life. In R. S. Wyer (Ed.), The automaticity of everyday life: Advances in social cognition (Vol. 10 , pp. 1-61). Hillsdale, NJ: Erlbaum.

Bargh, J. A. (1999). The cognitive monster: The case against the control lability of automatic stereotype effects. In S. Chaiken \& Y. Trope (Eds.), Dual-process theories in social psychology (pp. 361-382). New York: Guilford Press.

Bargh, J. A., Chen, M., \& Burrows, L. (1996). Automaticity of social behavior: Direct effects of construct and stereotype activation on action. Journal of Personality and Social Psychology, 7l, 230-244.

Bargh, J. A., \& Pietromonaco, P. (1982). Automatic information processing and social perception: The influence of trait information presented outside of conscious awareness. Journal of Personality and Social Psychology, 43, 437-449.

Blair, I. V. (2000). Implicit stereotypes and prejudice. In G. Moskowitz (Ed.), Cognitive social psychology: The Princeton symposium on the legacy and future of social cognition (pp. 359-374). Hillsdale, NJ: Erlbaum.

Blair, I., \& Banaji, M. (1996). Automatic and controlled process in stereotype priming. Journal of Personality and Social Psychology, 70 , $1142-1163$.

Blair, I. V,, Ma, J. E., \& Lenton, A. P. (2001). Imagining stereotypes away: The moderation of implicit stereotypes through mental imagery. Journal of Personality and Social Psychology, 81, 828-841.

Blanchard, F. A., Lilly, T., \& Vaughn, L. A. (1991). Reducing the expression of racial prejudice. Psychological Science, 2, 101-105.

Brewer, M. B., Dull, V., \& Lui, L. (1981). Perceptions of the elderly: Stereotypes as prototypes. Journal of Personality and Social Psychology, 4I, 656-670.

Chaiken, S., \& Trope, Y. (Eds.). (1999). Dual-process theories in social psychology. New York: Guilford Press.

Chen, M., \& Bargh, J. A. (1997). Nonconscious behavioral confirmation processes: The self-fulfilling consequences of automatic stereotype activation. Journal of Experimental Social Psychology, 33, 541-560.

Clark, H. H. (1996). Using language. Cambridge, England: Cambridge University Press.

Crosby, F., Bromley, S., \& Saxe, L. (1980). Recent unobtrusive studies of black and white discrimination and prejudice: A literature review. Psychological Bulletin, 87, 546-563.

Dasgupta, N., \& Greenwald, A. G. (2001). On the malleability of automatic attitudes: Combating automatic prejudice with images of admired and disliked individuals. Journal of Personality and Social Psychology, 81, $800-814$.

Dasgupta, N., McGhee, D. E., Greenwald, A. G., \& Banaji, M. R. (2000). Automatic preference for white Americans: Eliminating the familiarity explanation. Journal of Experimental Social Psychology, 36, 316-328.

Devine, P. G. (1989). Stereotypes and prejudice: Their automatic and controlled components. Journal of Personality and Social Psychology, 56, 5-18.

Devine, P. G., \& Baker, S. M. (1991). Measurement of racial stereotype subtyping. Personality and Social Psychology Bulletin, 17, 44-50.

Devine, P. G., \& Monteith, M. J. (1993). The role of discrepancyassociated affect in prejudice reduction. In D. M. Mackie \& D. L. Hamilton (Eds.), Affect, cognition. and stereotyping: Interactive processes in intergroup perception (pp. 317-344). San Diego, CA: Academic Press.

Devine, P. G., \& Monteith, M. J. (1999). Automaticity and control in stereotyping. In S. Chaiken \& Y. Trope (Eds.), Dual-process theories in social psychology (pp. 339-360). New York: Guilford Press.

Devine, P. G., Monteith, M. J., Zuwerink, J. R., \& Elliot, A. J. (1991). Prejudice with and without compunction. Journal of Personality and Social Psychology, 60, 817-830.

Devine, P. G., Plant, E. A., Amodio, D. M., Harmon-Jones, E., \& Vance, S. L. (2001). Exploring the relationship between implicit and explicit race bias: The role of motivations to respond without prejudice. Manuscript submitted for publication.

Dovidio, J. F., Kawakami, K., \& Gaertner, S. L. (2000). Reducing contemporary prejudice: Combating explicit and implicit bias at the individual and intergroup level. In S. Oskamp (Ed.), Reducing prejudice and discrimination (pp. 137-163). Hillsdale, NJ: Erlbaum.

Dovidio, J., Kawakami, K., Johnson, C., Johnson, B., \& Howard, A (1997). On the nature of prejudice: Automatic and controlled processes. Journal of Experimental Social Psychology, 33, 510-540.

Fazio, R. H., Jackson, J. R., Dunton, B. C., \& Williams, C. J. (1995) Variability in automatic activation as an unobtrusive measure of racial attitudes: A bona fide pipeline? Journal of Personality and Social Psychology, 69, 1013-1027.

Galinsky, A. D., \& Moskowitz,G. B. (2000). Perspective-taking decreasing stereotype expression, stereotype accessibility, and in-group favoritism. Journal of Personality and Social Psychology, 78, 708-724.

Gilbert, D. T., \& Hixon, J. G. (1991). The trouble of thinking: Activation and application of stereotypic beliefs. Journal of Personality and Social Psychology, 60, 509-517.

Greenwald, A. G., \& Banaji, M. R. (1995). Implicit social cognition: Attitudes, self-esteem, and stereotypes. Psychological Review, 102 4-27.

Greenwald, A. G., McGhee, D. E., \& Schwartz, J. L. K. (1998). Measuring individual differences in implicit cognition: The Implicit Association Test. Journal of Personality and Social Psychology, 74, 1464-1480.

Hamilton, D. L., \& Sherman, J. W. (1994). Stereotypes. In R. S. Wyer Jr. \& T. K. Srull (Eds.), Handbook of social cognition (2nd ed., Vol. 2, pp. 1-68). Hillsdale, NJ: Erlbaum.

Hardin, C. D., \& Conley, T. D. (2000). A relational approach to cognition: Shared experience and relationship affirmation in social cognition. In G. Moskowitz (Ed.), Cognitive social psychology: The Princeton symposium on the legacy and future of social cognition (pp. 3-17). Hillsdale, NJ: Erlbaum.

Hardin, C. D., \& Higgins, E. T. (1996). Shared reality: How social verification makes the subjective objective. In R. M. Sorrentino \& E. T. Higgins (Eds.), Handbook of motivation and cognition: The interpersonal context (Vol. 3 pp. 28-84). New York: Guilford Press.

Hardin, C. D., \& Rothman, A. J. (1997). Rendering accessible information relevant: The applicability of everyday life. In R. S. Wyer Jr. (Ed.), The automaticity of everyday life (pp. 143-156). Hillsdale, NJ: Erlbaum.

Higgins, E. T., \& McCann, C. D. (1984). Social encoding and subsequent attitudes, impressions, and memory: "Context-driven" and motivational aspects of processing. Journal of Personality and Social Psychology, 47, 26-39.

Higgins, T. E., \& Rholes, W. S. (1978). "Saying is believing": Effects of message modification on memory and liking for the person described. Journal of Experimental Social Psychology, 14, 363-378. 
Isaacs, E. A., \& Clark, H. H. (1987). References in conversation between experts and novices. Journal of Experimental Psychology: General, 116, 26-37.

Karpinski, A., \& Hilton J. L. (2001). Attitudes and the Implicit Associations Test. Journal of Personality and Social Psychology, 81, 774-788.

Kawakami, K., Dovidio, J. F., Moll, J., Hermsen, S., \& Russin, A. (2000). Just say no (to stereotyping): Effect of training in the negation of stereotypic associations on stereotype activation. Journal of Personality and Social Psychology, 78, 871-888.

Kinder, D. R., \& Sanders, L.M. (1996). Divided by color: Racial politics and democratic ideals. Chicago: University of Chicago Press.

Krauss, R. M., \& Fussell, S. R. (1991). Perspective-taking in communication: Representations of others' knowledge in reference. Social Cognition, 9, 2-24.

Krauss, R. M., \& Fussell, S. R. (1996). Social psychological models of interpersonal communication. In E. T. Higgins \& A. Kruglanski (Eds.), Social psychology: A handbook of basic principles (pp. 655-701). New York: Guilford Press.

Lepore, L., \& Brown, R. (1997). Category and stereotype activation: Is prejudice inevitable? Journal of Personality and Social Psychology, 72 , 275-287.

Locke, V., MacLeod, C., \& Walker, I. (1994). Automatic and controlled activation of stereotypes: Individual differences associated with prejudice. British Journal of Social Psychology, 33, 29-46.

Lowery, B. S., Hardin, C. D., \& Sinclair, S. (2000). [Self-reports of interethnic contact]. Unpublished raw data.

Macrae, C. N., Bodenhausen, G. V., Milne, A. B., Thorn, T. M. J., \& Castelli, L. (1997). On the activation of social stereotypes: The moderating role of processing objectives. Joumal of Experimental Social Psychology. 33, 471-489.

Maurer, K. L., Park, B., \& Rothbart, M. (1995). Subtyping versus subgrouping processes in stereotype representation. Journal of Personality and Social Psychology, 69, 812-824.

McCann, C. D., \& Hancock, R. D. (1983). Self-monitoring in communicative interactions: Social cognitive consequences of goal-directed message modification. Journal of Experimental Social Psychology, 19, 109121.

McCann, C. D., \& Higgins, E. T. (1992). Personal and contextual factors in communication: A review of the "communication game." In G. Semin \& K. Fiedler (Eds.), Language and social cognition (pp. 144-172). London: Sage.

McConahay, J. B., Hardee, B. B., \& Batts, V. (1981). Has racism declined in America? It depends on who is asking and what is asked. Journal of Conflict Resolution, 25, 563-579.

Monteith, M. (1993). Self-regulation of prejudiced responses: Implications for progress in prejudice-reduction efforts. Journal of Personality and Social Psychology, 65, 469-485.

Moskowitz, G. B., Gollwitzer, P. M., Wasel, W., \& Schaal, B. (1999). Preconscious control of stereotype activation through chronic egalitarian goals. Journal of Personality and Social Psychology, 77, 167-184.

Moskowitz, G. B., Salomon, A. R., \& Taylor, C. M. (2000). Preconsciously controlling stereotyping: Implicitly activated egalitarian goals prevent the activation of stereotypes. Social Cognition, 18, 151-177.

Pham, L., \& Hardin, C. D. (2001). The interpersonal function of negative social perception. Manuscript submitted for publication.

Plant, E. A., \& Devine, P. G. (1998). Internal and external motivation to respond without prejudice. Journal of Personality and Social Psychology, 3, 811-832.

Pratto, F., Sidanius, J., Stallworth, L. M., \& Malle, B. F. (1994). Social dominance orientation: A personality variable predicting social and political attitudes. Journal of Personality and Social Psychology, 67, $741-763$

Ratcliff, R. (1993). Methods for dealing with reaction time outliers. Psychological Bulletin, 114, 510-532.

Richeson, J. A., \& Ambady, N. (1999). Implicit associations in context: Effects of group membership and situational roles. Unpublished manuscript.

Rudman, L. A., Greenwald, A. G., Mellot, D. S., \& Schwartz, J. L. K (1999). Measuring the automatic components of prejudice: Flexibility and generality of the implicit association test. Social Cognition. 17. $437-465$.

Schuman, H., Steeh, S., Bobo, L., \& Krysan, M. (1997). Racial attitudes in America: Trends and interpretations (rev. ed.). Cambridge, MA: Harvard University Press.

Schwarz, N. (1994). Judgment in a social context: Biases, shortcomings, and the logic of conversation. In M. P. Zanna (Ed.), Advances in experimental social psychology (Vol. 26, pp. 123-162). San Diego, CA: Academic Press.

Sears, D. O., Citrin, J., Cheleden, S. V., \& van Laar, C. (1999). Cultural diversity and multicultural politics: Is ethnic balkanization psychologically inevitable? In D. A. Prentice \& D. T. Miller (Eds.), Cultural divides: Understanding and overcoming group conflict (pp. 35-79). New York: Russell Sage.

Sears, D. O., \& van Laar, C. (1999). Black exceptionalism in a culturally diverse society. Unpublished manuscript, University of California, Los Angeles.

Sinclair, L., \& Kunda, Z. (1999). Reactions to a Black professional: Motivated inhibition and activation of conflicting stereotypes. Journal of Personality and Social Psychology, 77, 885-904.

Sinclair, S. (1999). The interpersonal basis of self-stereotyping. Unpublished doctoral dissertation, University of Califomia, Los Angeles.

Sinclair, S., Lowery, B. S., \& Hardin, C. D. (2001). The effect of relationship concerns on automatic social tuning. Unpublished manuscript, University of Virginia at Charlottesville.

Snyder, M. (1974). The self-monitoring of expressive behavior. Journal of Personality and Social Psychology, 30, 526-537.

Spencer, S. J., Fein, S., Wolfe, C. T., Fong, C., \& Dunn, M. A. (1998). Automatic activation of stereotypes: The role of self-image threat. Personality and Social Psychology Bulletin, 24, 1139-1152.

Sperber, D., \& Wilson, D. (1987). Precis of relevance: Communication and cognition. Behavioral \& Brain Sciences, 10. 697-710.

Uleman, J. S., \& Moskowitz, G. B. (1994). Unintended effects of goals on unintended inferences. Journal of Personality and Social Psychology, 66, 490-501.

Wilson, T. D., Lindsey, S., \& Schooler, T. Y. (2000). A model of dual attitudes. Psychological Review, 107, 101-126.

Wittenbrink, B., Judd, C. M., \& Park, B. (1997). Evidence for racial prejudice at the implicit level and its relationship with questionnaire measures. Journal of Personality and Social Psychology, 72, 262-274.

Wittenbrink, B., Judd, C. M., \& Park, B. (2001). Spontaneous prejudice in context: Variability in automatically activated attitudes. Journal of Personality and Social Psychology, 81, 815-827. 


\section{Appendix}

White-Negative and Black-Positive Critical Page

\begin{tabular}{|c|c|c|}
\hline $\begin{array}{c}\text { White/American } \\
\text { OR Unpleasant }\end{array}$ & & $\begin{array}{l}\text { Black/American } \\
\text { OR Unpleasant }\end{array}$ \\
\hline & $\begin{array}{l}\text { CHANDA (Black) } \\
\text { bomb (unpleasant) } \\
\text { TAMEISHA (Black) } \\
\text { gentle (pleasant) } \\
\text { HEIDI (White) } \\
\text { integrity (pleasant) } \\
\text { SHARISE (Black) } \\
\text { honor (pleasant) } \\
\text { DONNA (White) } \\
\text { affection (pleasant) } \\
\text { MEREDITH (White) } \\
\text { sunise (pleasant) } \\
\text { SUSIE (White) } \\
\text { crash (unpleasant) } \\
\text { SHANNON (White) } \\
\text { failure (unpleasant) } \\
\text { YOLANDA (Black) } \\
\text { brutal (unpleasant) } \\
\text { KATIE (White) } \\
\text { honest (pleasant) } \\
\text { SHANIQUA (Black) } \\
\text { noble (pleasant) } \\
\text { RASHONDA (Black) } \\
\text { disease (unpleasant) } \\
\text { BROOK (White) } \\
\text { health (pleasant) } \\
\text { SARA (White) } \\
\text { ridicule (unpleasant) } \\
\text { PATTY (White) } \\
\text { success (pleasant) } \\
\text { LATOYA (Black) } \\
\text { abuse (unpleasant) } \\
\text { CRYSTAL (White) } \\
\text { rotten (unpleasant) } \\
\text { STEPHANIE (White) } \\
\text { filth (unpleasant) } \\
\text { MELANIE (White) } \\
\text { torture (unpleasant) } \\
\text { NICHELLE (Black) } \\
\text { paradise (pleasant) }\end{array}$ & \\
\hline
\end{tabular}

Note. The words in parentheses indicate the category the words belong to. These cues were not present in the materials seen by participants.

Received June 14, 2000

Revision received April 19, 2001

Accepted April 19, 2001 